\title{
The first metatarsophalangeal joint in gout: a systematic review and meta-analysis
}

\author{
Sarah Stewart ${ }^{1 *}$, Nicola Dalbeth ${ }^{2}$, Alain C. Vandal ${ }^{3,4}$ and Keith Rome
}

\begin{abstract}
Background: The aim of this review was to qualitatively synthesise studies that have investigated characteristics of the first metatarsophalangeal joint ( $\left(1^{\text {st }}\right.$ MTP) in gout and to undertake a meta-analysis to estimate the average prevalence of acute $1^{\text {st }}$ MTP arthritis across studies in people with gout.

Methods: Studies published in English were included if they involved participants who had a diagnosis of gout and presented original findings relating to the following outcome measures associated with the $1^{\text {st }}$ MTP: epidemiology; clinical features; structural and functional characteristics; and microscopic and imaging features.

Results: Forty-five studies were included in the qualitative synthesis. $1^{\text {st }}$ MTP pain was a prominent feature in people with gout. People with $1^{\text {st }}$ MTP gout reported walking- and general-disability. Structural and functional characteristics of $1^{\text {st }}$ MTP gout included hallux valgus, osteoarthritis, and restricted joint motion. Successful crystal aspiration ranged from 81 to $91 \%$ and positive crystal identification via microscopy ranged from 83 to $93 \%$ in patients with a history of $1^{\text {st }}$ MTP gout. Imaging features were common at the $1^{\text {st }}$ MTP including the double contour sign, tophi and erosions. Eleven studies involving 2,325 participants were included in the meta-analysis, providing an estimate of the average prevalence of acute $1^{\text {st }}$ MTP arthritis across studies of $73 \%$ ( $95 \%$ prediction interval 40-92\%; range 48-97\%; $\left.\right|^{2}=93 \%$ ).
\end{abstract}

Conclusions: $1^{\text {st }}$ MTP acute arthritis is highly prevalent in people with gout and has a substantial impact on patient-reported pain and disability. Gout affects the structure and function of the $1^{\text {st }}$ MTP. Microscopic and imaging studies have demonstrated crystal deposition and joint damage at the $1^{\text {st }}$ MTP in people with gout.

Keywords: First metatarsophalangeal joint, Gout

\section{Background}

Gout, one of the most common forms of inflammatory arthritis in middle-aged men, is caused by monosodium urate (MSU) crystal deposition in joints and soft tissue [1]. Clinically, gout is characterised by painful flares of acute monoarthritis interspersed with asymptomatic periods. If left untreated, gout can progress to a chronic arthritis with tophus formation and joint damage [2].

Gout is well recognised by its predilection to affect the first metatarsophalangeal joint ( $1^{\text {st }}$ MTP). Acute episodes of gouty arthritis at the $1^{\text {st }}$ MTP are often referred to as podagra [3]. In recent decades, lifestyle and dietary factors associated with hyperuricaemia have become increasingly

\footnotetext{
* Correspondence: sarah.stewart@aut.ac.nz

${ }^{1}$ Faculty of Health and Environmental Sciences, Health \& Rehabilitation Research Institute, Auckland University of Technology, Private Bag 92006, Auckland 1142, New Zealand

Full list of author information is available at the end of the article
}

widespread, as has the global burden of gout [4]. Gout has a major impact on health-related quality of life [5] and its tendency to affect the foot is reflected in the high levels of foot-related disability and impairment [6].

Despite the well-recognised susceptibility of the $1^{\text {st }}$ MTP to acute arthritis in gout, evident by its inclusion in several gout diagnostic and classification criteria [7-10], a formal synthesis of the prevalence of acute $1^{\text {st }}$ MTP arthritis in this condition has yet to be undertaken. Furthermore, the burden of $1^{\text {st }}$ MTP involvement on patient-reported outcomes in gout is unclear. Despite the significant role of the $1^{\text {st }}$ MTP during normal gait, particularly the forward transfer of body weight during propulsion $[11,12]$, it is also unclear to what extent the structure and function of the joint is compromised in people with gout. This systematic review aimed to qualitatively synthesise studies which have investigated characteristics of the 
$1^{\text {st }}$ MTP in gout and to undertake a meta-analysis to provide a pooled estimate for the average prevalence of acute $1^{\text {st }}$ MTP arthritis in gout across studies.

\section{Methods}

\section{Search strategy}

A comprehensive electronic search was completed in March 2015 using the following databases: Scopus (1960 to March 2015), Medline (1966 to March 2015), CINAHL (1937 to March 2015), SportsDiscus (1985 to March 2015), the Cochrane Library, ACR abstracts (2009 to 2013) and EULAR abstracts (2002 to 2012) with the search terms presented in Table 1 . This search was supplemented with hand-searching of reference lists of all potentially eligible full-text articles and selected review articles.

\section{Selection criteria}

All potentially eligible articles were screened by a single author (SS) at title, abstract, and full-text stages. The review was conducted with reference to the Preferred Reporting Items for Systematic review and Meta-Analysis protocols (PRISMA) statement [13]. Studies considered for this review were published in peer-reviewed journals and limited to randomised controlled trials, cohort studies, case-control studies and cross-sectional studies. Peerreviewed conference proceedings and abstracts were also considered for inclusion. Case reports, case series with $<5$ cases and review articles were excluded.

The inclusion criteria included studies published in English, adults over 18 years old and which involved participants who had a diagnosis of gout. Included studies presented original findings relating to the following outcome measures: incidence or prevalence of acute inflammatory arthritis at the $1^{\text {st }}$ MTP; clinical features of acute gouty arthritis, intercritical gout and chronic gouty arthropathy (including tophaceous gout) at the $1^{\text {st }}$ MTP; structural and functional characteristics of the $1^{\text {st }}$ MTP;

Table 1 Search terms

\begin{tabular}{ll}
\hline$\# 1$ & Gout* OR uric OR urate OR hyperuric*OR toph* \\
\#2 & "First metatarsophalangeal" OR "first metatarsal phalangeal" OR \\
hallux OR "big toe" OR "first toe" OR digit OR podagra OR "1st & mtp*" OR 1mtp* OR foot OR feet \\
\#3 $\quad \begin{array}{l}\text { Imaging OR sonograph* OR ultraso* OR "doppler" OR radiograph* } \\
\text { OR xray OR "magnetic resonance" OR mri OR "computed } \\
\text { tomograph*" OR ct OR "dect" OR "dual energy" }\end{array}$ \\
\#4 Histol* OR microscop* \\
\#5 & Function* OR gait OR walk* OR "plantar pressure" OR motion \\
\hline
\end{tabular}

Final search term: \#1 AND \#2 AND (\#3 OR \#4 OR \#5)

(gout* OR uric OR urate OR hyperuric*OR toph*) AND ("first metatarsophalangeal" OR "first metatarsal phalangeal" OR hallux OR "big toe" OR "first toe" OR digit OR podagra OR "1st mtp*" OR 1mtp* OR foot OR feet) AND ((imaging OR sonograph* OR ultraso* OR "doppler" OR radiograph* OR xray OR "magnetic resonance" OR mri OR "computed tomograph" OR ct OR "dect" OR "dual energy") OR (histol* OR microscop*) OR (function* OR gait OR walk* OR "plantar pressure" OR motion)) microscopy of the $1^{\text {st }}$ MTP; and imaging features of the $1^{\text {st }}$ MTP including MSU crystals, bone disease and synovial disease. Studies investigating outcomes as a measure of pharmacological, non-pharmacological and surgical intervention efficacy were excluded. Studies which assessed the $1^{\text {st }}$ MTP amongst other joints, but did not report outcome measures specifically relating to the $1^{\text {st }}$ MTP, were also excluded.

\section{Data extraction}

The following data was extracted from all included papers: the first author's last name, publication year, country where the study was conducted, the study design and aim(s), the outcome measure(s) reported and the characteristics of the gout participants including: sample size, gender, mean age (years), mean disease duration (years) and the method of diagnosis.

\section{Statistical analysis}

A meta-analysis was conducted to obtain an estimate of the prevalence of acute arthritis at the $1^{\text {st }}$ MTP in people with gout at any point during the course of their disease. Due to the expected high prevalence of acute $1^{\text {st }}$ MTP arthritis, a double arcsine transformation was adopted to address variance instability. This transformation method is the preferred transformation option as it avoids an undue large weight for studies [14]. The meta-analysis was carried out using the inverse of the variance of the transformed proportion as study weight. The pooled transformed prevalence was transformed back for the final presentation of the data. The $95 \%$ prediction intervals for the average estimate of prevalence was also reported [15]. A random-effects model was used and the degree of heterogeneity was evaluated using the Higgins $\mathrm{I}^{2}$ statistic which was interpreted as follows: $\mathrm{I}^{2}$ of $25 \%=$ low heterogeneity, $\mathrm{I}^{2}$ of $50 \%=$ medium heterogeneity, $\mathrm{I}^{2}=$ $75 \%=$ high heterogeneity [16]. Statistical analysis was undertaken in MetaXL version 2.0 (EpiGear International Pty Ltd, Brisbane, Australia).

\section{Results \\ Description of studies}

Figure 1 shows a flow chart of the literature search. The initial search identified 576 papers through database searching and 12 papers from conference abstracts. Following the removal of 160 duplicates, 428 papers were screened, of which 240 papers were considered for further examination based upon the title and abstract. Forty-five studies met the criteria and were included in the review (including 4 conference abstracts published in peer-reviewed journals [17-20] and 2 English abstracts from non-English papers [21, 22]). Of the 45 studies, 8 were longitudinal cohort studies, 20 crosssectional studies, 10 case-control studies, 5 retrospective 


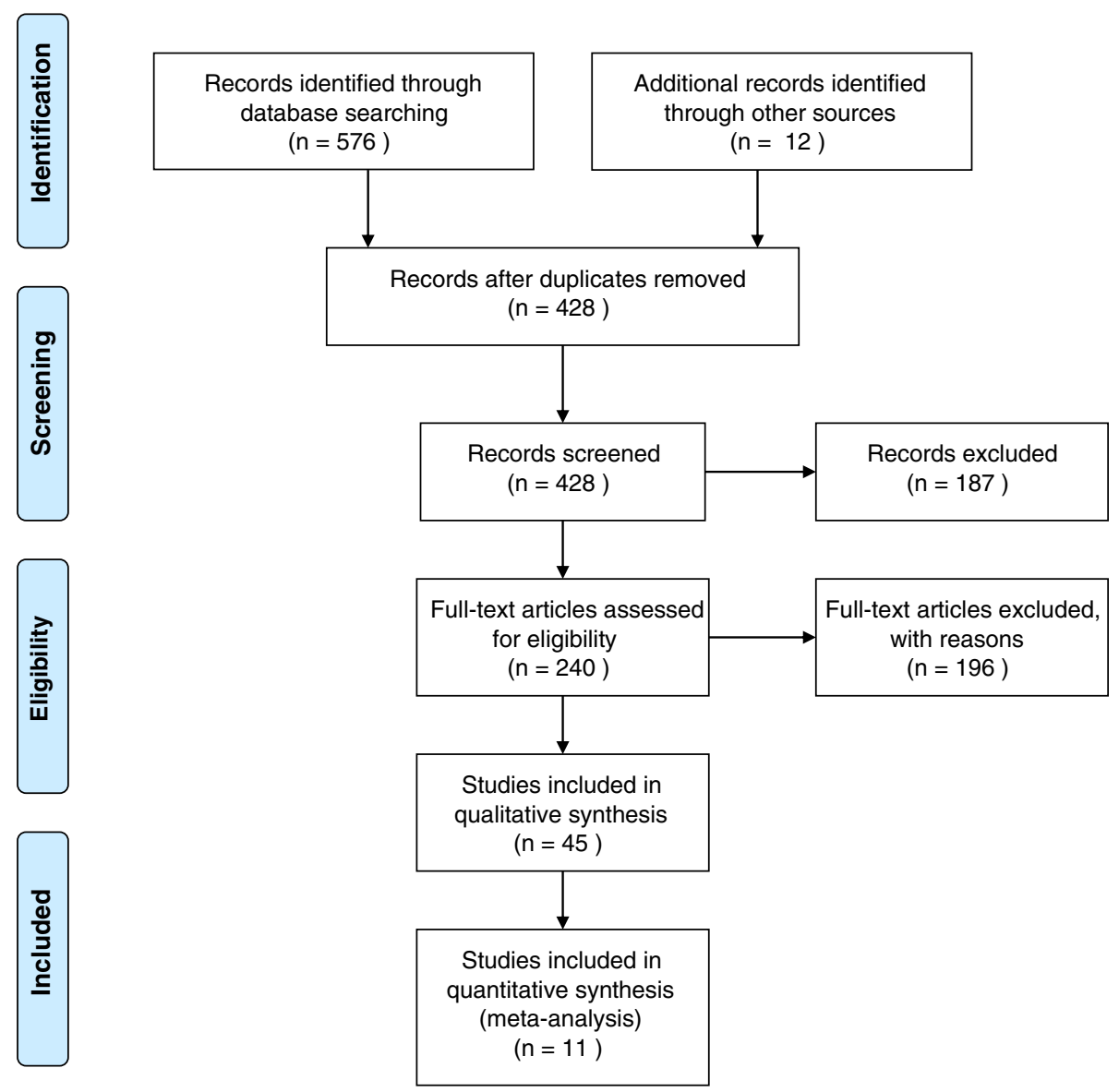

Fig. 1 PRISMA flowchart

studies, and 2 randomised clinical trials. Details of the 45 included studies are displayed in Table 2.

The 45 included studies involved 44 different groups of gout participants (two studies used the same participants $[23,24])$ totalling a pooled sample size of 5,478 participants. Thirty-eight studies involving 5,067 participants reported gender of which 4,348 (86 \%) were male. Thirty-six studies reported mean participant age which ranged from 28 years to 69 years. Twenty-nine studies reported disease duration which ranged from newly diagnosed gout to 22 years.

Five studies did not report how patients with gout were diagnosed $[17,19,21,25,26]$. Fifteen studies, totalling 1,773 participants included only patients with gout who were diagnosed via microscopic identification of MSU crystals in synovial fluid/tophus aspirates. Fifteen studies, totalling 1,116 participants, diagnosed gout via the 1977 ACR criteria [7] in which participants either had MSU-proven gout or met 6 of the 12 clinical criteria. Of these studies, nine reported the number of crystal-proven participants (300/656 $(46 \%))$. Two of these studies knowingly included patients with gout who did not meet the ACR criteria $(n=36)$. The remaining seven studies included in the review diagnosed patients with gout using other methods detailed in Table 2 [18, 20, 27-31].

The 45 studies reported on one or more of the following outcome measures relating to $1^{\text {st }}$ MTP gout: epidemiology ( $n=14$, including $n=11$ articles reporting on the prevalence of acute $1^{\text {st }}$ MTP arthritis at any point during the course of the disease which were included in the meta-analysis), clinical characteristics $(n=8)$, structural characteristics $(n=2)$, functional characteristics $(n=4)$, microscopy $(n=7)$; and imaging features $(n=19)$.

\section{Epidemiology}

Acute $1^{\text {st }}$ MTP arthritis presenting as the manifestation of gout at disease onset, ranged from 43 to $76 \%$ $[20,32-35]$. The frequency of acute $1^{\text {st }}$ MTP arthritis as the initial manifestation of gout was not significantly different between genders [34-36]. However, acute $1^{\text {st }}$ MTP arthritis at any point during the disease was significantly more frequent in men $(68.6 \%)$ compared to women $(31.8 \%)[34,36]$. Two studies reported 54 and $72 \%$ of 
Table 2 Details of papers included in review

\begin{tabular}{|c|c|c|c|c|c|}
\hline Author & Location & Study design & Aim & Characteristics of gout participants & Outcome measures relevant to review \\
\hline Bellamy [27] & Canada & $\begin{array}{l}\text { Longitudinal } \\
\text { cohort }\end{array}$ & Natural progression of 1MTP acute flares & $\begin{array}{l}N=11 \\
\text { Male } 100 \% \\
\text { Mean age } 55 \text { years } \\
\text { Mean disease duration } 4 \text { years } \\
\text { Diagnosis: "patients presenting with classical features } \\
\text { of acute podagra, had experienced prior attacks of } \\
\text { gouty arthritis and were known to be or have been } \\
\text { hyperuricaemic". }\end{array}$ & Clinical characteristics of 1MTP gout \\
\hline Carter [32] & USA & Cross-sectional & $\begin{array}{l}\text { The presence of synovial inflammation during } \\
\text { intercritical gout }\end{array}$ & $\begin{array}{l}N=72 \\
\text { Male } 90 \% \\
\text { Mean age } 56 \text { years } \\
\text { Mean disease duration } 10 \text { years } \\
\text { Diagnosis: ACR criteria (incl. } 42 \% \text { crystal proven) }\end{array}$ & Epidemiology of 1MTP gout \\
\hline Dalbeth [58] & New Zealand & Cross-sectional & Scoring bone erosion in gout using $C T$ imaging & $\begin{array}{l}N=25 \\
\text { Male } 75 \% \\
\text { Median age } 60 \text { years } \\
\text { Median disease duration } 21 \text { years } \\
\text { Diagnosis: ACR criteria (incl. } 44 \% \text { crystal proven) }\end{array}$ & Imaging features of the 1MTP in gout \\
\hline Dalbeth [55] & New Zealand & Cross-sectional & $\begin{array}{l}\text { Relationship between radiographic joint damage } \\
\text { and MSU crystal deposition using DECT imaging }\end{array}$ & $\begin{array}{l}N=92 \\
\text { Male } 93 \% \\
\text { Mean age } 58 \text { years } \\
\text { Mean disease duration } 22 \text { years } \\
\text { Diagnosis: ACR criteria (incl. } 48 \% \text { crystal proven) }\end{array}$ & Imaging features of the 1 MTP in gout \\
\hline Dalbeth [54] & New Zealand & Cross-sectional & $\begin{array}{l}\text { Comparison of DECT MSU deposition in people } \\
\text { with gout and people with asymptomatic } \\
\text { hyperuricaemia }\end{array}$ & $\begin{array}{l}N=33 \\
\text { Male }=85 \% \\
\text { Mean age } 61 \text { years } \\
\text { Mean disease duration } 11 \text { years } \\
\text { Diagnosis: MSU crystal proven }\end{array}$ & Imaging features of the 1 MTP in gout \\
\hline Deesomchok [34] ${ }^{*}$ & Thailand & Cross-sectional & Clinical pattern of gout in females and males & $\begin{array}{l}N=194 \\
\text { Male } 89 \% \\
\text { Mean age } 59 \text { (F) } 52 \text { (M) years } \\
\text { Mean disease duration } 3 \text { (F) } 10 \text { (M) years } \\
\text { Diagnosis: ACR criteria (incl. } 81 \% \text { crystal proven) }\end{array}$ & Epidemiology of 1MTP gout \\
\hline DeSouza [36] & Brazil & Cross-sectional & $\begin{array}{l}\text { Clinical and laboratory features of gout in men } \\
\text { and women }\end{array}$ & $\begin{array}{l}N=58 \\
\text { Male } 53 \% \\
\text { Mean age } 64 \text { (F) } 61(M) \text { years } \\
\text { Mean disease duration } 9 \text { (F) } 14 \text { (M) years } \\
\text { Diagnosis: ACR criteria (\% crystal proven not reported) }\end{array}$ & Epidemiology of 1MTP gout \\
\hline Grahame [29]* & UK & Retrospective & Characteristics of patients with gout & $\begin{array}{l}N=354 \\
\text { Male } 90 \% \\
\text { Mean age NR } \\
\text { Mean disease duration NR } \\
\text { Diagnosis: patients with "recurrent acute episodes } \\
\text { of arthritis in the presence of hyperuricaemia" }\end{array}$ & Epidemiology of 1MTP gout \\
\hline
\end{tabular}


Table 2 Details of papers included in review (Continued)

\begin{tabular}{|c|c|c|c|c|c|}
\hline Hall [28]* & USA & $\begin{array}{l}\text { Longitudinal } \\
\text { cohort }\end{array}$ & Epidemiology of gout and hyperuricaemia & $\begin{array}{l}N=86 \\
\text { Male } 87 \% \\
\text { Mean age } 58 \text { years } \\
\text { Mean disease duration } 9 \text { years } \\
\text { Diagnosis: patients who met two of the following: a } \\
\text { typical attack of arthritis characterised by acute pain, } \\
\text { usually accompanied by swelling and heat, lasting } \\
\text { from a few day sot } 2 \text { weeks, and followed by complete } \\
\text { remission of symptoms; an attack of arthritis exhibiting } \\
\text { a striking and prompt response to therapeutic colchicine; } \\
\text { the presence of hyperuricaemia. }\end{array}$ & Epidemiology of 1MTP gout \\
\hline Howard [67] & USA & Cross-sectional & $\begin{array}{l}\text { Reliability of ultrasound for tophi and double } \\
\text { contour sign }\end{array}$ & $\begin{array}{l}N=50 \\
\text { Male } 100 \% \\
\text { Mean age } 69 \text { years } \\
\text { Mean disease duration NR } \\
\text { Diagnosis: ACR criteria (\% crystal proven not reported) }\end{array}$ & Imaging features of the $1 \mathrm{MTP}$ in gout \\
\hline Huppertz $[31]^{*}$ & Germany & Case-control & $\begin{array}{l}\text { Diagnostic accuracy of DECT and ultrasound } \\
\text { for detecting MSU crystal deposition }\end{array}$ & $\begin{array}{l}N=39 \text { Male NR } \\
\text { Mean age NR } \\
\text { Disease duration newly diagnosed } \\
\text { Diagnosis: Janssens score [10] of }>8 \text { or MSU crystal } \\
\text { proven ( } 46 \%)\end{array}$ & Imaging features of the $1 \mathrm{MTP}$ in gout \\
\hline Janssens $[10]^{*}$ & Netherlands & Cross-sectional & Validation of a diagnostic model to predict gout & $\begin{array}{l}N=209 \\
\text { Male } 89.5 \% \\
\text { Mean age } 59 \text { years } \\
\text { Mean disease duration NR } \\
\text { Diagnosis: MSU crystal proven }\end{array}$ & Epidemiology of $1 \mathrm{MTP}$ gout \\
\hline $\begin{array}{l}\text { Kawenoki-Minc } \\
\text { [21] }\end{array}$ & Poland & Cross-sectional & $\begin{array}{l}\text { Incidence of radiographic evidence of } \\
\text { degenerative articular changes in patients } \\
\text { with gout }\end{array}$ & $\begin{array}{l}N=262 \\
\text { Male NR } \\
\text { Mean age NR } \\
\text { Mean disease duration NR } \\
\text { Diagnosis: not reported }\end{array}$ & Imaging features of the $1 \mathrm{MTP}$ in gout \\
\hline Kennedy [30] & London & Cross-sectional & $\begin{array}{l}\text { MSU crystal presence in aspirated 1MTP } \\
\text { joint fluid }\end{array}$ & $\begin{array}{l}N=31 \\
\text { Male } 100 \% \text { Mean age } 61 \text { years } \\
\text { Mean disease duration } 10 \text { years } \\
\text { Diagnosis: patients who had "previously had podagra" } \\
\text { including } 52 \% \text { who were MSU crystal proven }\end{array}$ & Microscopy in 1MTP gout \\
\hline Kienhorst [37] & Netherlands & $\begin{array}{l}\text { Longitudinal } \\
\text { cohort }\end{array}$ & Validation of clinical diagnosis of 1MTP gout & $\begin{array}{l}N=123 \\
\text { Male } 85 \% \\
\text { Mean age } 59 \text { years } \\
\text { Mean disease duration NR } \\
\text { Diagnosis: MSU crystal proven }\end{array}$ & Clinical characteristics of $1 \mathrm{MTP}$ gout \\
\hline Kim [68] & Korea & Cross-sectional & DECT presence of MSU deposition & $\begin{array}{l}N=101 \\
\text { Male } 95 \% \\
\text { Mean age NR } \\
\text { Mean disease duration NR } \\
\text { Diagnosis: ACR criteria (\% crystal proven not reported) }\end{array}$ & Imaging features of the $1 \mathrm{MTP}$ in gout \\
\hline
\end{tabular}


Table 2 Details of papers included in review (Continued)

\begin{tabular}{|c|c|c|c|c|}
\hline Kim [43] & Korea & $\begin{array}{l}\text { Longitudinal } \\
\text { cohort }\end{array}$ & $\begin{array}{l}\text { Comparison of clinical outcomes of arthrodesis } \\
\text { and tophi excision \& evaluate MRI features of } \\
\text { tophaceous gout }\end{array}$ & $\begin{array}{l}N=15 \\
\text { Male } 67 \% \\
\text { Mean age } 57 \text { yearsMean disease duration NR } \\
\text { Diagnosis: MSU crystal proven }\end{array}$ \\
\hline Lally [35]* & USA & Retrospective & $\begin{array}{l}\text { Comparison of gouty arthritis in men } \\
\text { and women }\end{array}$ & $\begin{array}{l}N=98 \\
\text { Male } 77 \% \\
\text { Mean age } 63 \text { (F) } 63 \text { (M) years } \\
\text { Mean disease duration } 5 \text { (F) } 14 \text { (M) years } \\
\text { Diagnosis: MSU crystal proven }\end{array}$ \\
\hline Mallinson [25] & Canada & Retrospective & $\begin{array}{l}\text { Distribution of MSU crystal deposition in gout } \\
\text { using DECT imaging }\end{array}$ & $\begin{array}{l}N=148 \\
\text { Male } 82 \% \\
\text { Mean age } 61 \text { years } \\
\text { Mean disease duration NR } \\
\text { Diagnosis: not reported }\end{array}$ \\
\hline Mijiyawa [38]* & Togo & Retrospective & Characteristics of patients with gout & $\begin{array}{l}N=106 \\
\text { Male } 99 \% \\
\text { Mean age } 53 \text { years } \\
\text { Mean disease duration } 8 \text { yearsDiagnosis: ACR criteria } \\
\text { (incl. } 17 \% \text { crystal proven) }\end{array}$ \\
\hline Kang [41] & Korea & $\begin{array}{l}\text { Longitudinal } \\
\text { cohort }\end{array}$ & $\begin{array}{l}\text { Ultrasound characteristics of gout \& efficacy } \\
\text { of intra-articular steroid injection for acute } \\
\text { 1MTP flares }\end{array}$ & $\begin{array}{l}N=21 \\
\text { Male } 86 \% \\
\text { Mean age } 64 \text { years } \\
\text { Mean disease duration NR } \\
\text { Diagnosis: ACR criteria (\% crystal proven not reported) }\end{array}$ \\
\hline Naredo [50] & Spain & Case-control & Diagnostic value of ultrasound for gout & $\begin{array}{l}N=91 \\
\text { Male } 100 \% \\
\text { Mean age } 56 \text { years } \\
\text { Mean disease duration } 7 \text { years } \\
\text { Diagnosis: MSU crystal proven }\end{array}$ \\
\hline Ordonez [17] & Spain & Cross-sectional & $\begin{array}{l}\text { Reliability of ultrasound in detection of } \\
\text { lesion at 1MTP in gout }\end{array}$ & $\begin{array}{l}N=15 \\
\text { Male NR } \\
\text { Mean age NR } \\
\text { Mean disease duration NR } \\
\text { Diagnosis: not reported }\end{array}$ \\
\hline Ottaviani [52] & France & $\begin{array}{l}\text { Longitudinal } \\
\text { cohort }\end{array}$ & $\begin{array}{l}\text { Ultrasonography showing disappearance of } \\
\text { MSU crystals following urate lowering therapy }\end{array}$ & $\begin{array}{l}N=16 \\
\text { Male } 100 \% \\
\text { Mean age } 61 \text { years } \\
\text { Mean disease duration } 7 \text { years } \\
\text { Diagnosis: MSU crystal proven }\end{array}$ \\
\hline Pascual [46] & Spain & Cross-sectional & $\begin{array}{l}\text { MSU crystal presence in aspirated 1MTP } \\
\text { joint fluid }\end{array}$ & $\begin{array}{l}N=101 \\
\text { Male } 98 \% \\
\text { Mean age } 56 \text { years } \\
\text { Mean disease duration } 5 \text { years } \\
\text { Diagnosis: ACR criteria (incl. } 77 \% \text { crystal proven) }\end{array}$ \\
\hline
\end{tabular}

Clinical characteristics of 1MTP gout: Functional characteristics of Imaging features of the 1MTP in gout

Epidemiology of 1MTP gout

Microscopy in 1MTP gout

Epidemiology of 1MTP gout

Clinical characteristics of 1MTP gout; Imaging features of the 1MTP in gout

Imaging features of the 1MTP in gout

Imaging features of the 1MTP in gout

Imaging features of the 1MTP in gout

Microscopy in 1MTP gout

Diagnosis: ACR criteria (incl. 77 \% crystal proven) 
Table 2 Details of papers included in review (Continued)

\begin{tabular}{|c|c|c|c|c|c|}
\hline Pascual [69] & Spain & $\begin{array}{l}\text { Longitudinal } \\
\text { cohort }\end{array}$ & $\begin{array}{l}\text { Disappearance of MSU crystals following } \\
\text { urate lowering therapy }\end{array}$ & $\begin{array}{l}N=18 \\
\text { Male } 100 \% \\
\text { Mean age } 56 \text { years } \\
\text { Mean disease duration } 10 \text { years } \\
\text { Diagnosis: MSU crystal proven }\end{array}$ & Microscopy in 1MTP gout \\
\hline $\begin{array}{l}\text { Pelaez-Ballestas } \\
{[9]^{*}}\end{array}$ & Mexico & Cross-sectional & $\begin{array}{l}\text { Identifying criteria for diagnosis of } \\
\text { chronic gout }\end{array}$ & $\begin{array}{l}N=549 \\
\text { Male } 96 \% \\
\text { Mean age } 50 \text { years } \\
\text { Mean disease duration } 12 \text { years } \\
\text { Diagnosis: MSU crystal proven }\end{array}$ & Epidemiology of 1MTP gout \\
\hline Radak-Perovic [22] & Serbia & Case-control & $\begin{array}{l}\text { Comparison of ultrasound and } x \text {-ray for } \\
\text { detection of 1MTP erosions }\end{array}$ & $\begin{array}{l}N=30 \\
\text { Male NR } \\
\text { Mean age NR } \\
\text { Mean disease duration NR } \\
\text { Diagnosis: ACR criteria (\% crystal proven not reported) }\end{array}$ & Imaging features of the 1MTP in gout \\
\hline Roddy [24] & UK & Case-control & Concomitant gout and osteoarthritis & $\begin{array}{l}N=164 \\
\text { Male } 81 \% \\
\text { Mean age } 63 \text { years } \\
\text { Mean disease duration } 10 \text { years } \\
\text { Diagnosis: } 91 \% \text { met ACR criteria (\% crystal proven } \\
\text { not reported) }\end{array}$ & $\begin{array}{l}\text { Epidemiology of 1MTP gout; Functional } \\
\text { characteristics of 1MTP gout }\end{array}$ \\
\hline Roddy [51] & UK & Cross-sectional & Ultrasound characteristics of gout & $\begin{array}{l}N=40 \\
\text { Male } 78 \% \\
\text { Mean age } 65 \text { years } \\
\text { Mean disease duration } 13 \text { years } \\
\text { Diagnosis: ACR criteria (incl. } 53 \% \text { crystal proven) }\end{array}$ & Imaging features of the 1MTP in gout \\
\hline Roddy [18] & UK & Cross-sectional & $\begin{array}{l}\text { Prevalence of hallux valgus, foot pain and } \\
\text { disability in gout }\end{array}$ & $\begin{array}{l}N=1184 \\
\text { Male } 78 \% \\
\text { Mean age } 66 \text { years } \\
\text { Mean disease duration } 12 \text { years } \\
\text { Diagnosis: "Patients who had consulted their GP } \\
\text { about gout or been prescribed allopurinol or } \\
\text { colchicine within the preceding } 2 \text { years" }\end{array}$ & $\begin{array}{l}\text { Clinical characteristics of 1MTP gout; } \\
\text { Structural characteristics of 1MTP gout }\end{array}$ \\
\hline Roddy [23] & UK & Case-Control & $\begin{array}{l}\text { Nodal osteoarthritis and the risk of } \\
\text { developing gout }\end{array}$ & $\begin{array}{l}N=164 \\
\text { Male } 81 \% \\
\text { Mean age } 63 \text { years } \\
\text { Mean disease duration } 10 \text { years } \\
\text { Diagnosis: } 91 \% \text { met ACR criteria (\% crystal proven } \\
\text { not reported) }\end{array}$ & $\begin{array}{l}\text { Clinical characteristics of 1MTP gout; } \\
\text { Structural characteristics of 1MTP gout }\end{array}$ \\
\hline Rome [45] & New Zealand & Case-control & $\begin{array}{l}\text { Functional and biomechanical characteristics } \\
\text { of gait in people with gout }\end{array}$ & $\begin{array}{l}N=25 \\
\text { Male } 75 \% \\
\text { Mean age } 61 \text { years } \\
\text { Mean disease duration } 22 \text { years } \\
\text { Diagnosis: ACR criteria (incl. } 44 \% \text { crystal proven) }\end{array}$ & Functional characteristics of 1MTP gout \\
\hline
\end{tabular}

Diagnosis: 91 \% met ACR criteria (\% crystal proven not reported)

Mean age 65 years

Mean disease duration 13 years

Diagnosis: ACR criteria (incl. 53 \% crystal proven)

$N=164$

(TMTP gout; Structural characteristics of 1MTP gout

met ACR criteria (\% crystal proven

reported)

Mean age 61 years

Diagnosis: ACR criteria (incl. $44 \%$ crystal proven) 
Table 2 Details of papers included in review (Continued)

\begin{tabular}{|c|c|c|c|c|c|}
\hline Rouault [39]* & USA & Case-control & 1MTP aspiration as a diagnostic tool for gout & $\begin{array}{l}N=23 \text { Male NR } \\
\text { Mean age NR } \\
\text { Mean disease duration NR } \\
\text { Diagnosis: MSU crystal proven }\end{array}$ & $\begin{array}{l}\text { Epidemiology of } 1 \text { MTP gout; Microscopy } \\
\text { in 1MTP gout }\end{array}$ \\
\hline Sivera [47] & Spain & Cross-sectional & Feasibility of 1MTP aspiration for gout diagnosis & $\begin{array}{l}N=22 \\
\text { Male } 82 \% \\
\text { Mean age } 61 \text { years } \\
\text { Mean disease duration NR } \\
\text { Diagnosis: MSU crystal proven }\end{array}$ & Microscopy in 1MTP gout \\
\hline Sun [53] & China & Cross-sectional & DECT imaging features of gout & $\begin{array}{l}N=80 \\
\text { Male } 94 \% \\
\text { Mean age } 52 \text { years } \\
\text { Mean disease duration } 5 \text { years } \\
\text { Diagnosis: ACR criteria (\% crystal proven not reported) }\end{array}$ & Imaging features of the 1MTP in gout \\
\hline Taylor [33]* & $\begin{array}{l}\text { Multinational, } \\
\text { multicentre }\end{array}$ & Cross-sectional & Clinical, laboratory, imaging findings in gout & $\begin{array}{l}N=509 \\
\text { Male } 86 \% \\
\text { Mean age } 60 \text { years } \\
\text { Median disease duration } 6 \text { years } \\
\text { Diagnosis: MSU crystal proven }\end{array}$ & $\begin{array}{l}\text { Epidemiology of 1MTP gout; Clinical } \\
\text { characteristics of 1MTP gout }\end{array}$ \\
\hline Thiele [56] & USA & Case-control & Sonographic features of gout & $\begin{array}{l}N=16 \\
\text { Male } 81 \% \\
\text { Mean age } 64 \text { years } \\
\text { Mean disease duration NR } \\
\text { Diagnosis: MSU crystal proven }\end{array}$ & Imaging features of the 1MTP in gout \\
\hline Thiele [57] & USA & Retrospective & $\begin{array}{l}\text { Detection of erosions with ultrasound and } \\
\text { conventional radiography in chronic gout }\end{array}$ & $\begin{array}{l}N=42 \\
\text { Male NR } \\
\text { Mean age NR } \\
\text { Mean disease duration NR } \\
\text { Diagnosis: MSU crystal proven }\end{array}$ & Imaging features of the 1MTP in gout \\
\hline Vreju [19] & Romania & $\begin{array}{l}\text { Longitudinal } \\
\text { cohort }\end{array}$ & Importance of ultrasound in gout diagnosis & $\begin{array}{l}N=23 \\
\text { Male } 53 \% \\
\text { Mean age } 53 \text { years } \\
\text { Disease duration }<1 \text { year } \\
\text { Diagnosis: not reported }\end{array}$ & Imaging features of the 1MTP in gout \\
\hline Wang [26] & Taiwan & $\begin{array}{l}\text { Randomised } \\
\text { controlled trial }\end{array}$ & $\begin{array}{l}\text { Comparison of arthroscopic removal of 1MTP } \\
\text { MSU crystals with medical treatment alone }\end{array}$ & $\begin{array}{l}N=28 \\
\text { Male } 100 \% \\
\text { Mean age } 28 \text { years } \\
\text { Mean disease duration } 2 \text { years } \\
\text { Diagnosis: not reported }\end{array}$ & $\begin{array}{l}\text { Clinical characteristics of 1MTP gout; } \\
\text { Functional characteristics of 1MTP gout }\end{array}$ \\
\hline Wallace $[7]^{*}$ & USA & Cross-sectional & $\begin{array}{l}\text { Development of a criteria for the classification } \\
\text { of arthritis due to primary gout }\end{array}$ & $\begin{array}{l}N=178 \\
\text { Male } 86 \% \\
\text { Mean age } 56 \text { years } \\
\text { Mean disease duration } 10 \text { years } \\
\text { Diagnosis: } 88 \% \text { met ACR criteria (incl. } 43 \% \\
\text { crystal proven) }\end{array}$ & Epidemiology of 1MTP gout \\
\hline
\end{tabular}

\section{$N=16$}

Mean age 64 years

Mean age NR

Mean disease duration NR

Male $53 \%$

Mean age 53 years

Diagnosis: not reported

$\mathrm{V}=28$

Mean age 28 years

Mean disease duration 10 years

crystal proven) 
Table 2 Details of papers included in review (Continued)

\begin{tabular}{|c|c|c|c|c|c|}
\hline Weinberger [48] & USA & Case-control & MSU crystals in aspirated 1MTP joint fluid & $\begin{array}{l}N=9 \\
\text { Male } 100 \% \\
\text { Mean age } 54 \text { years } \\
\text { Mean disease duration } 2 \text { years } \\
\text { Diagnosis: MSU crystal proven }\end{array}$ & Microscopy in 1MTP gout \\
\hline Wright [42] & Ireland & Case-control & $\begin{array}{l}\text { Comparison of ultrasound and } x \text {-ray for } \\
\text { detection of erosions in gout }\end{array}$ & $\begin{array}{l}N=39 \\
\text { Male } 100 \% \\
\text { Mean age } 52 \text { years } \\
\text { Mean disease duration } 12 \text { years } \\
\text { Diagnosis: ACR criteria (incl. } 28 \% \text { crystal proven) }\end{array}$ & Imaging features of the 1MTP in gout \\
\hline Zleik [20] & USA & $\begin{array}{l}\text { Longitudinal } \\
\text { cohort }\end{array}$ & $\begin{array}{l}\text { Risk \& predictors additional flares in newly } \\
\text { diagnosed gout }\end{array}$ & $\begin{array}{l}N=158 \\
\text { Male } 73 \% \\
\text { Mean age } 59 \text { years } \\
\text { Mean disease duration Newly diagnosed } \\
\text { Diagnosis: via the New York, Rome or ACR criteria } \\
\text { (\% crystal proven not reported) }\end{array}$ & Epidemiology of 1MTP gout \\
\hline
\end{tabular}


patients with gout, respectively, experienced acute arthritis isolated to the $1^{\text {st }}$ MTP $[33,37]$.

Eleven studies reported the prevalence of acute $1^{\text {st }}$ MTP arthritis at any point during the course of the disease and were included in the meta-analysis $[7,9,10,28$, 29, 31, 33-35, 38, 39]. The studies provided a pooled sample size of 2,464 participants. In total, $87 \%$ were male with a mean age ranging between 50 and 63 years old. Mean or median disease duration was reported by eight studies and ranged from newly diagnosed to 14 years [7, 9, 28, 31, 33-35, 38]. Fifty-six percent of 2,110 participants from 10 studies demonstrated aspirate proven gout $[7,9,10,28,31,33-35,38,39]$. The reported prevalence of acute arthritis at any point during the course of the disease ranged from 48 to $97 \%$. The pooled prevalence estimate of acute $1^{\text {st }}$ MTP arthritis across studies was $73 \%$ (95\% prediction interval: 40-92 \%). The heterogeneity was high with an $\mathrm{I}^{2}$ of $93 \%$ (95\% CI: $90 \%-96 \%$ ). Figure 2 presents the forest plot showing the pooled prevalence estimate of acute $1^{\text {st }}$ MTP arthritis in gout across the included studies.

\section{Clinical characteristics}

Four studies reported the characteristics of acute $1^{\text {st }}$ MTP arthritis, which included rapid onset of extremely severe pain and tenderness with moderate swelling, erythema and inflammation [27, 37, 40]. Seventy-nine percent of patients reported onset within 1 day [37]. Erythema was observed in $95 \%$ of patients with acute $1^{\text {st }}$ MTP arthritis [37]. In a study following the natural progression of acute $1^{\text {st }}$ MTP arthritis for 7 days in 11 patients, improvements in erythema and juxta-articular skin temperature were observed by day four, while $1^{\text {st }}$ MTP pain and swelling improved in most by day five [27]. Two studies reported pain during acute $1^{\text {st }}$ MTP arthritis using $100 \mathrm{~mm}$ Visual Analogue Scales (VAS)
[37, 41]. Mean patient-reported pain ranged from 54.3 to $71.1 \mathrm{~mm}[37,41]$.

During intercritical periods, in the absence of acute symptoms, a significantly greater number of patients with gout reported current $1^{\text {st }}$ MTP pain compared to healthy matched controls (16\% vs. $6 \%$, respectively) [23]. One study reported $72 \%$ of patients with long-standing gout, with a mean of 12 years disease duration, reported $1^{\text {st }}$ MTP pain in the previous month [18]. During clinical examination of $781^{\text {st }}$ MTPs from 39 patients with currently asymptomatic gout, $35 \%$ of joints demonstrated mild tenderness, $9 \%$ demonstrated moderate tenderness and $6 \%$ demonstrated marked tenderness [42].

High levels of $1^{\text {st }}$ MTP pain were reported in patients with chronic tophaceous gout affecting the $1^{\text {st }}$ MTP $[26,43]$, with patients scoring a mean of $7.6 \mathrm{~cm}$ to $7.8 \mathrm{~cm}$ on a $10 \mathrm{~cm}$ pain VAS [43].

\section{Structural characteristics}

Structure of the $1^{\text {st }}$ MTP has also been assessed in people with gout through the presence of self-reported hallux valgus, a structural forefoot deformity involving lateral deviation of the hallux at the $1^{\text {st }}$ MTP $[18,23]$. A case-control study involving 164 patients with gout found that self-reported hallux valgus was significantly more common in patients with gout [23]. However, a larger cohort study involving 1,184 gout participants revealed $36 \%$ of patients had self-reported hallux valgus, which the authors reported was similar to the general population and not related to gout-specific factors [18].

\section{Functional characteristics}

Moderate to high levels of general disability and walking disability were reported using $100 \mathrm{~mm}$ VAS in patients with current acute $1^{\text {st }}$ MTP arthritis (mean $60.0 \mathrm{~mm}$ to $64.1 \mathrm{~mm}$ ) [41]. Similarly, when using the Hallux Metatarsophalangeal-Interphalangeal section of

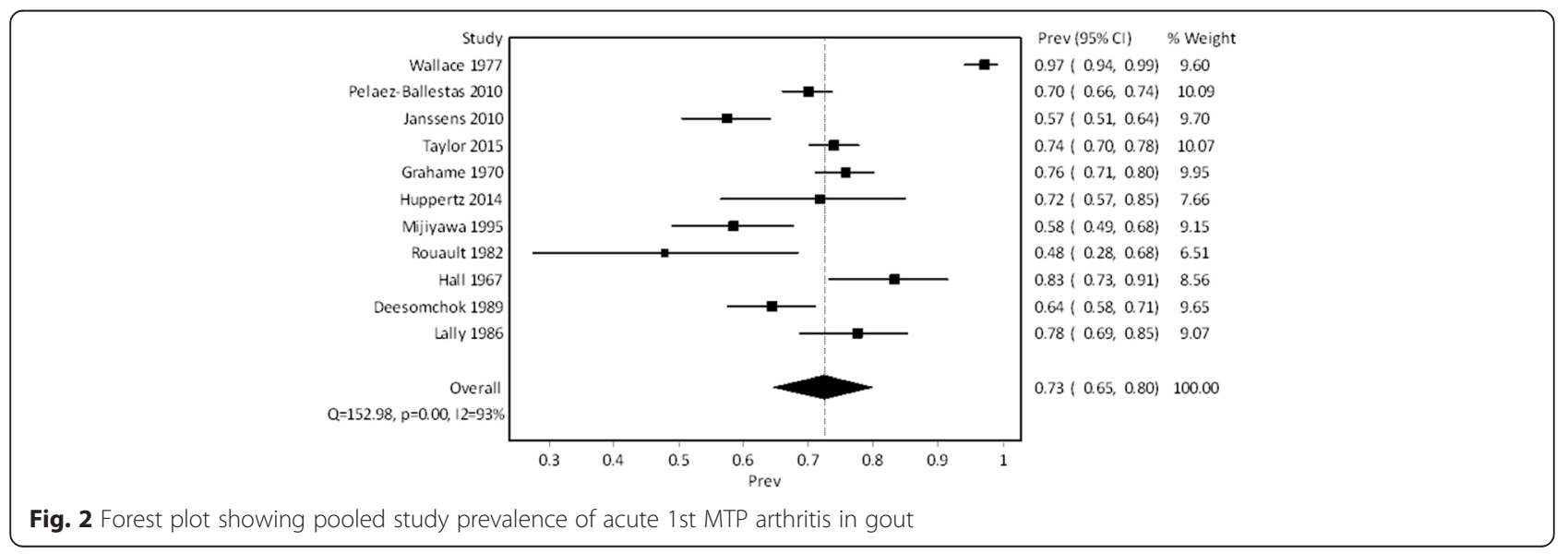


the American Orthopaedic Foot and Ankle Society (AOFAS) scale [44], which provides a total score out of 100 based on pain, range of motion, joint instability and alignment, and activity- and footwear-related limitations, people with $1^{\text {st }}$ MTP tophi scored between 65 and 61 out of 100 , where 100 indicates an absence of pain and any joint, activity or footwear limitation [43].

A study on 164 people with gout found a significant association between acute $1^{\text {st }}$ MTP arthritis and the presence $1^{\text {st }}$ MTP osteoarthritis, defined as restricted motion, bony swelling and/or crepitus [24]. In a further study of patients with severe tophaceous gout the mean (SD) total range of motion at the $1^{\text {st }}$ MTP was $19^{\circ}$, which reduced to $14^{\circ}$ in joints which also demonstrated severe cartilage loss [43].

A study assessing foot function in 25 patients with long-standing chronic gouty arthropathy using in-shoe plantar pressure analysis found peak plantar pressure beneath the first metatarsal was greater in the gout group, although not significantly [45]. However, peak plantar pressure and pressure-time integrals beneath the hallux were significantly reduced in the gout group when compared to the controls, which the authors proposed reflected an attempt to offload pain at the $1^{\text {st }}$ MTP [45].

\section{Microscopy}

The success of joint fluid acquisition for the purposes of microscopic identification of MSU crystals from the $1^{\text {st }}$ MTP ranged from 81 to $91 \%$ [30, 46, 47]. The presence of MSU crystals in $1^{\text {st }}$ MTP fluid ranged from 83 to $89 \%$ of currently asymptomatic $1^{\text {st }}$ MTPs in patients with gout with a history of acute 1st MTP arthritis [39, 46]. In patients with gout with no history of acute 1st MTP arthritis, 52 to $67 \%$ of aspirated 1st MTPs were positive for crystals $[30,39,48]$. In patients experiencing current acute 1st MTP arthritis the presence of MSU crystals ranged from 85 to $93 \%[47,49]$.

The occurrence of acute 1st MTP arthritis as a diagnostic feature has been compared with the presence of MSU crystals in aspirated 1st MTP fluid [10, 37]. Based on clinical characteristics of acute 1st MTP arthritis in 159 patients, general practitioners diagnosed $98 \%$ of patients as having gout [37]. When validated against the presence of MSU crystals, a sensitivity of 0.99 and a specificity of 0.08 was demonstrated [37]. In a study of 328 patients with monoarthritis, Janssens [10] reported that the 1st MTP as the location of the monoarthritis was an independent predictor of MSU crystal presence [10].

\section{Imaging features}

\section{Urate crystal deposition}

Ultrasonography allows the visualisation of MSU crystal deposition along the surface of articular cartilage, referred to as the 'double contour sign', the presence of which ranged from 22 to $87.5 \%$ at the 1st MTP [41, 42, 50-52]. Naredo [50] noted the double contour sign was more frequent at the dorsal aspect of the 1st MTP (62\%) compared to the plantar aspect (23\%).

Dual-energy computed tomography (DECT) may be less sensitive than ultrasound due to the lower spatial resolution [31]. In a study of 39 patients (79 \% with newly diagnosed gout) DECT detected urate crystals in $26 \%$ of 1 st MTPs, and ultrasound in $74 \%$ of the same joints [31]. The presence of MSU deposition using DECT increased from $26 \%$ of joints in newly diagnosed gout [25], to $36 \%$ after 5 years disease duration [53], and $54 \%$ in patients with 11 years mean duration [54]. In patients with tophaceous gout and a mean disease duration of 22 years, MSU crystals were present in $38 \%$ of 184 1st MTPs [55].

In a DECT study assessing feet with current flares, the authors reported crystal deposition in $41 \%$ of 1 st MTPs in patients with 1st MTP flares, compared to $27 \%$ of 1st MTPs in patients with current ankle flares [53]. The presence of DECT MSU crystal deposition was found to be a risk factor for acute 1st MTP arthritis $(\mathrm{OR}=3.38$; $)$ [53].

\section{Tophi}

In sonographic studies, the presence of tophi in 1st MTPs of people with gout ranged from 50 to $100 \%$ $[41,42,50,52,56,57]$. Thiele and Schlesinger [56] noted tophi were more often seen medial and dorsal to the joint with a distinct pattern in which unformed microparticles were seen in the dorsal proximal recess and central area while formed tophi were more frequent in the medial compartment and impinging on the dorsal proximal phalanx [56]. Using MRI, a study of 15 patients with 1st MTP tophaceous gout, reported that the medial sesamoid was the most common location for tophaceous infiltration (seen in $47 \%$ of patients), followed by the first metatarsal shaft (40\%) and lateral sesamoid (33\%) [43]. In the majority of patients (57 \%) tophi were observed both extra-articularly and intra-articularly within the 1st MTP.

\section{Bone disease}

In patients with long-standing tophaceous gout, erosions on conventional radiography were noted in $79 \%$ of 1st MTPs [55]. Other radiographic features of bone damage have been observed frequently in the 1st MTP joints in people with gout including spur formation (40\% of joints), joint space narrowing (39\%), osteophytes (44\%), sclerosis (73\%) and periosteal new bone formation (13\%) [55]. A study of 262 patients with gout reported radiographic proven osteoarthritis (defined as destruction of the articular 
surfaces) in $44 \%$ of 1st MTPs and found a significant correlation between osteoarthritis and acute arthritis at this joint [21].

Sonographic evidence of bone erosion in 1st MTPs ranged from 40 to $67 \%$ in patients with gout [22, 41, 42, 56, 57]. Wright [42] reported $92 \%$ of detected erosions were present on the medial aspect of the metatarsal head, with $7 \%$ on the dorsal metatarsal head, and the remaining $2 \%$ on the medial aspect of the proximal phalangeal base. Erosions at the 1st MTP can be multifocal or unifocal and generally measure at least $2 \mathrm{~mm}$ in diameter [41, 42]. Thiele and Schlesinger [56] noted all erosions at the 1st MTP were adjacent to tophaceous material.

Using MRI, Kim [43] reported erosions and intraosseous involvement present in the first metatarsal shaft of $40 \%$ of patients with symptomatic 1st MTP tophaceous gout. Using conventional CT, Dalbeth [58] reported $78 \%$ of 1st MTPs had erosions present at the first metatarsal head, and $34 \%$ had erosions at the proximal phalanx. The proportions of eroded bone were also greater at the metatarsal head compared to the proximal phalanx and were higher in those with clinically-evident tophi.

\section{Synovial disease}

Synovial disease, in the form of joint effusion, synovial hypertrophy, and synovitis has been assessed using both gray-scale and power Doppler ultrasound $[41,42,51,56]$. Joint effusion, which has been observed in 29 to $74 \%$ of 1st MTPs in people with gout $[41,42,51,56]$, is less specific for gout and has been seen at a similar rate in other rheumatic conditions (64 to $73 \%$ ) [42, 56]. Similarly, synovial hypertrophy is seen at a similar rate in gouty 1 st MTPs (53 to $87 \%$ ) [41, 42, 51], and other rheumatic conditions (64\%) [42]. Synovitis, which can be assessed using power Doppler ultrasound has been shown to be more sensitive than clinical assessment (18\% vs. $5 \%$, respectively) [51]. Synovitis has been reported to occur at the 1st MTP with a mild Doppler signal in $15 \%$, moderate signal in $18 \%$ and marked signal in $10 \%$ [42]. Synovitis occurs at a significantly greater frequency in 1st MTPs in those joints with acute arthritis, with Kang [41] reporting $95 \%$ of 1st MTPs with acute arthritis demonstrated mild to moderate power Doppler signals. However, synovitis is not specific to gout and is seen in 18 to $50 \%$ of other inflammatory joint diseases $[42,56]$.

\section{Discussion}

The historical observation of gout as a condition specifically affecting the 1st MTP is reflected in modern epidemiological literature, and is evident by the pooled $73 \%$ prevalence estimate of 1st MTP acute arthritis reported in the meta-analysis of 11 studies. The clinical diversity between these studies, which is generally considered inevitable in meta-analyses [59], may explain the wide range of estimated prevalence values and account for the high heterogeneity observed. The included studies represented patients with gout from a wide range of countries, resulting in different participant demographics, genetic factors and lifestyle factors. Additionally, disease duration of gout participants varied considerably and is likely to impact the calculated prevalence estimate, as longer disease duration would increase the likelihood of experiencing an episode of acute 1st MTP arthritis. Furthermore, only $42 \%$ of participants included in the meta-analysis were diagnosed with gout using the gold standard MSU crystal identification $[7,9,10,28,31,34,35,38,39]$. The differences in study designs adopted by the included studies (e.g. cohort, cross-sectional, case-control, retrospective and randomised controlled trial) may also have contributed to the increased heterogeneity. Nevertheless, this prevalence estimate provides useful quantitative data which corroborates the traditional notion that gout is a condition with frequent manifestations at the $1^{\text {st }}$ MTP.

Pain experienced during acute 1st MTP arthritis is considerable $[27,37,41]$, and remains present following the resolution of acute symptoms $[18,42]$. Outcome measurement methods used for measuring 1st MTP pain varied from 5-point Likert scales [27], visual analogue scales $[37,41]$, simply recording whether 1 st MTP pain was present or absent [23], to measuring tenderness with palpation [42]. However, it appears that 1st MTP pain is a chronic foot problem in people with gout, which is further reflected by the sub-clinical joint inflammation observed during intercritical periods [42, 51]. In patients with 1st MTP tophaceous gout, high levels of pain are coupled with reduced joint function [26, 43]. Although it is unclear whether these clinical symptoms are a consequence of pain-avoidance, joint damage, synovial inflammation, mechanical obstruction by tophi, or a combination of these factors, the clinical implications of symptomatic 1st MTP gout on the ability to undertake everyday weight-bearing activities, such as walking, are recognised as important features of the disease [41]. People with gout walk significantly slower and demonstrate gait patterns consistent with 1st MTP pain-avoidance strategies [45]. Abnormal 1st MTP loading at toe-off in patients with gout may be further exacerbated by biomechanical strain as a result of MSU deposition within the 1st MTP flexor and extensor tendons $[53,60]$.

As the initiation of acute gouty arthritis is not possible in the absence of MSU crystals, the susceptibility of the 1st MTP to gout over other joints must be related to certain factors which predispose to the precipitation and deposition of crystals at this site. It has been hypothesised that the predilection for MSU deposition and patient symptoms in the foot and ankle may be attributed to the biomechanical loading or physical stress during 
the normal gait cycle $[55,56,58,60]$. This is further emphasised in the distinct pattern of crystal deposition at the 1st MTP observed in imaging studies where MSU deposits have been reported to occur more often on the medial and dorsal aspects of the joint compared to the plantar aspect [50, 56, 61]. It has been proposed that this distinct pattern of crystal deposition at the 1st MTP may result from the shifting of tophaceous deposits with dorsiflexion during walking and their eventual clustering at pressure points within the joint [56].

Osteoarthritis observed at the 1st MTP has also been implicated in the co-occurrence of gout at this joint $[21,24]$. However, the distinction between joint damage caused by chronic gouty arthritis and osteoarthritic joint damage is unclear, particularly due to the high prevalence of 1st MTP osteoarthritis in the general population [62].

This review has a number of limitations. Firstly, the literature search and screening was conducted by a single reviewer. Secondly, the methodology adopted may have created a selection bias through the exclusion of nonEnglish language studies which may have resulted in an incompletely and potentially biased set of evidence. In regard to the methodologies used in included studies, most were cross-sectional descriptive studies which provide lower-level evidence and limit investigation in to the cause-effect relationship between 1st MTP characteristics and gout. Many of the studies also involved small sample sizes. Furthermore, gout disease characteristics of participants in the included studies varied and the majority of participants were diagnosed based on clinical criteria. Although this reflects diagnostic methods employed in clinical practice, there are several limitations to current classification criteria [40] and the demonstration of MSU crystals in synovial/tophus aspirates remains the only method to permit a definitive diagnosis of gout [63]. Lastly, there is an absence of a recommended outcome measure to assess patient-reported outcomes relating specifically to the 1st MTP in gout research which makes comparisons between studies challenging.

This review highlights the need for future research which adopts standardised assessment approaches when investigating patient-reported outcomes specifically relating to the 1st MTP in gout. Advanced imaging may be implemented to determine the structural characteristics of the joint in relation to clinical features, particularly how 1st MTP involvement affects patient-reported outcomes and the ability to carry out daily activities, including walking. This may direct further research which investigates the biomechanical role of the 1st MTP in the frequent occurrence of gout at this joint. By recognising the local factors that contribute to the 1st MTPs susceptibility to crystal deposition and inflammation, further studies may assess non-pharmacological interventions that are specifically aimed at the 1st MTP including footwear, foot orthoses and foot-related health education which have previously been shown to be effective with generalfoot pain and disability in people with gout [64-66].

\section{Conclusion}

This review aimed to evaluate and summarise the findings from existing literature which assessed the 1st MTP in people with gout. This review confirms the long-standing notion that acute 1st MTP arthritis is highly prevalent in people with gout and has a substantial impact on patient-reported outcomes related to pain and disability. Current research also suggests that the structure and function of the 1st MTP is impaired in people with gout. This review highlights the importance of clinical, laboratory and imaging findings related to the 1st MTP in the diagnosis of gout in clinical practice and underlines the need for interventions that specifically target improvements in structure, function and patient-reported outcomes related to the 1st MTP in people with gout.

\section{Abbreviation \\ 1st MTP: First metatarsophalangeal joint.}

\section{Competing interests}

ND has received personal fees or grants from Takeda, Teijin, Menarini, Pfizer AstraZeneca, Ardea, and Fonterra. The other authors declare no competing interests.

\section{Authors' contributions}

SS was involved in the searches and eligibility checks, extracting of study data, conducting the meta-analysis interpreting the findings and drafting of the manuscript. ND was involved in the design of the review, interpretation of the findings and drafting of the manuscript. AV was involved in the design of the review, conducting the meta-analysis, interpreting the findings and drafting of the manuscript. KR was involved in the design of the review, interpretation of the findings and drafting of the manuscript. All authors read and approved the final manuscript.

\section{Acknowledgements \\ None.}

\section{Author details}

${ }^{1}$ Faculty of Health and Environmental Sciences, Health \& Rehabilitation Research Institute, Auckland University of Technology, Private Bag 92006, Auckland 1142, New Zealand. ${ }^{2}$ Department of Medicine, Faculty of Medical and Health Sciences, The University of Auckland, Private Bag 92019, Auckland 1142, New Zealand. ${ }^{3}$ Department of Biostatistics \& Epidemiology, School of Public Health \& Psychosocial Studies, Faculty of Health and Environmental Sciences, Auckland University of Technology, Private Bag 92006, Auckland 1142, New Zealand. ${ }^{4}$ Health Intelligence \& Informatics, Ko Awatea, Counties Manukau Health, Private Bag 93311, Auckland 1640, New Zealand.

Received: 3 July 2015 Accepted: 3 February 2016

Published online: 11 February 2016

\footnotetext{
References

1. Choi HK, Mount DB, Reginato AM. Pathogenesis of gout. Ann Intern Med. 2005;143(7):499.

2. Teng GG, Nair R, Saag KG. Pathophysiology, clinical presentation and treatment of gout. Drugs. 2006;66(12):1547.

3. Hippocrates. Genuine works of Hippocrates, vol. I \& II. New York: William Wood and Company; 1886.
} 
4. Smith E, Hoy D, Cross M, Merriman TR, Vos T, Buchbinder R, et al. The global burden of gout: estimates from the Global Burden of Disease 2010 study. Ann Rheum Dis. 2014;73(8):1470-6.

5. Scire CA, Manara M, Cimmino MA, Govoni M, Salaffi F, Punzi L, et al. Gout impacts on function and health-related quality of life beyond associated risk factors and medical conditions: results from the KING observational study of the Italian Society for Rheumatology (SIR). Arthritis Res Ther. 2013;15(5):R101.

6. Rome K, Frecklington M, McNair P, Gow P, Dalbeth N. Foot pain, impairment, and disability in patients with acute gout flares: a prospective observational study. Arthritis Care Res. 2012;64(3):384-8.

7. Wallace SL, Robinson H, Masi AT, Decker JL, McCarty DJ, Yü TF. Preliminary criteria for the classification of the acute arthritis of primary gout. Arthritis Rheum. 1977;20(3):895-900.

8. Decker JL. Report from the subcommittee on diagnostic criteria for gout. In: Population studies of the rheumatic diseases - Proceedings of the third International Symposium: 1968 1966; New York. Amsterdam: Excerpta Medica Foundation; 1966. p. 385-7.

9. Peláez-Ballestas I, Hernández Cuevas C, Burgos-Vargas R, Hernández Roque L, Terán L, Espinoza J, et al. Diagnosis of chronic gout: evaluating the American College of Rheumatology proposal, European league against rheumatism recommendations, and clinical judgment. J Rheumatol. 2010;37(8):1743-8.

10. Janssens HJEM, Fransen J, van de Lisdonk EH, van Riel PLCM, van Weel C, Janssen M. A diagnostic rule for acute gouty arthritis in primary care without joint fluid analysis. Arch Intern Med. 2010;170(13):1120-6.

11. Lebduska SR. Topographic and functional anatomy and biomechanics of the foot. Phys Med Rehabil. 2001;15(3):421-38.

12. Mann RA, Hagy JL. The function of the toes in walking, jogging and running. Clin Orthop Relat Res. 1979;142:24-9.

13. Moher D, Shamseer L, Clarke M, Ghersi D, Liberati A, Petticrew M, et al. Preferred reporting items for systematic review and meta-analysis protocols (PRISMA-P) 2015 statement. Syst Rev. 2015;4:1.

14. Barendregt JJ, Doi SA, Lee YY, Norman RE, Vos T. Meta-analysis of prevalence. Epidemiol Community Health. 2013;67:974-8.

15. Higgins JP, Thompson SG, Spiegelhalter DJ. A re-evaluation of randomeffects meta-analysis. J R Stat Soc A Stat Soc. 2009;172(1):137-59.

16. Higgins JP, Thompson SG. Quantifying heterogeneity in a meta-analysis. Stat Med. 2002:21(11):1539-58.

17. Ordoñez M, Peiteado D, Villalba A, Castillo-Gallego C, Martín-Mola E, Miguel E. Reliability of ultrasonography in the recognition of elementary characteristic lesions of gout in the first metatarsal phalangeal joint. Ann Rheum Dis. 2009;68(Suppl3):513.

18. Roddy E, Muller S, Rome K, Chandratre P, Hider S, Richardson J, et al. Chronic foot problems in people with gout: an observational study in primary care. Rheumatology. 2014;53(Suppl1):163.

19. Vreju F, Ciurea P, Anca R, Musetescu A. Metatarsophalangeal joint ultrasonography as a diagnostic tool for gout. Ann Rheum Dis. 2010; 69(Suppl3):715.

20. Zleik N, Michet $\mathrm{CJ}$, Khun H, Crowson CS, Matteson EL, Bongartz T. The risk of subsequent attacks in patients with incident gout: a population-based study. Arthritis Rheum. 2013;65(Suppl10):853.

21. Kawenoki-Minc E, Eyman E, Leo W, Weryńska-Przybylska J. Osteoarthrosis and spondylosis in gouty patients. Analysis of 262 cases of gout. Reumatologia. 1974;12(3):267.

22. Radak-Perović M, Savić V, Milutinović S, Zlatković-Svenda M. Ultrasonography of the first metatarsophalangeal joint in gout. Srpski Arhiv Za Celokupno Lekarstvo. 2011;139(3-4):161-4.

23. Roddy E, Zhang W, Doherty M. Gout and nodal osteoarthritis: a case-control study. Rheumatology (Oxford). 2008;47(5):732-3.

24. Roddy E, Zhang W, Doherty M. Are joints affected by gout also affected by osteoarthritis? Ann Rheum Dis. 2007;66(10):1374-7.

25. Mallinson PI, Reagan AC, Coupal T, Munk PL, Ouellette H, Nicolaou S. The distribution of urate deposition within the extremities in gout: a review of 148 dual-energy CT cases. Skeletal Radiol. 2014;43(3):277-81.

26. Wang C-C, Lien S-B, Huang G-S, Pan R-Y, Shen H-C, Kuo C-L, et al. Arthroscopic elimination of monosodium urate deposition of the first metatarsophalangeal joint reduces the recurrence of gout. Arthroscopy. 2009;25(2):153-8.

27. Bellamy N, Downie WW, Buchanan WW. Observations on spontaneous improvement in patients with podagra: implications for therapeutic trials of non-steroidal anti-inflammatory drugs. Br J Pharmacol. 1987;24(1):33-6.
28. Hall AP, Barry PE, Dawber TR, MCNamara PM. Epidemiology of gout and hyperuricemia: a long-term population study. Am J Med. 1967;42(1):28-37.

29. Grahame R, Scott JT. Clinical survey of 354 patients with gout. Ann Rheum Dis. 1970:29(5):461-8.

30. Kennedy TD, Higgens CS, Woodrow DF, Scott JT. Crystal deposition in the knee and great toe joints of asymptomatic gout patients. J R Soc Med. 1984;77(9):747-50.

31. Huppertz A, Hermann K-GA, Diekhoff T, Wagner M, Hamm B, Schmidt WA. Systematic staging for urate crystal deposits with dual-energy $\mathrm{CT}$ and ultrasound in patients with suspected gout. Rheumatol Int. 2014;34(6):763-71.

32. Carter JD, Patelli M, Anderson SR, Prakash N, Rodriquez EJ, Bateman $\mathrm{H}$, et al. An MRI assessment of chronic synovial-based inflammation in gout and its correlation with serum urate levels. Clin Rheumatol. 2015;34(2):345-51.

33. Taylor WJ, Fransen J, Jansen TL, Dalbeth N, Schumacher HR, Brown M, et al. Study for Updated Gout Classification Criteria (SUGAR): identification of features to classify gout. Arthritis Care Res. 2015. doi:10.1002/acr.22585.

34. Deesomchok $U$, Tumrasvin $T$. A clinical comparison of females and males with gouty arthritis. J Med Assoc Thailand. 1989;72(9):510-5.

35. Lally EV, Ho Jr G, Kaplan SR. The clinical spectrum of gouty arthritis in women. Arch Intern Med. 1986;146(11):2221-5.

36. DeSouza AWS, Fernandes V, Ferrari AJL. Female gout: clinical and laboratory features. J Rheumatol. 2005;32(11):2186-8.

37. Kienhorst LBE, Janssens HJEM, Fransen J, Lisdonk EHvd, Janssen M. Arthritis of the first metatarsophalangeal joint is not always gout: a prospective cohort study in primary care patients. Joint Bone Spine. 2014;81(4):342-6.

38. Mijiyawa M. Gout in patients attending the rheumatology unit of Lomé Hospital. Br J Rheumatol. 1995;34(9):843-6.

39. Rouault T, Caldwell DS, Holmes EW. Aspiration of the asymptomatic metatarsophalangeal joint in gout patients and hyperuricemic controls. Arthritis Rheum. 1982;25(2):209-12.

40. Taylor WJ, Fransen J, Jansen TL, Dalbeth N, Schumacher HR, Brown M, et al. Study for Updated Gout Classification Criteria (SUGAR): identification of features to classify gout. Arthritis Care Res (Hoboken). 2015. doi:10.1002/acr.22585.

41. Kang MH, Moon KW, Jeon YH, Cho SW. Sonography of the first metatarsophalangeal joint and sonographically guided intraarticular injection of corticosteroid in acute gout attack. J Clin Ultrasound. 2015;43(3):179-86.

42. Wright SA, Filippucci E, McVeigh C, Grey A, McCarron M, Grassi W, et al. High-resolution ultrasonography of the first metatarsal phalangeal joint in gout: a controlled study. Ann Rheum Dis. 2007;66(7):859-64.

43. Kim YS, Park EH, Lee HJ, Koh YG. First metatarsophalangeal joint arthrodesis for the treatment of tophaceous gouty arthritis. Orthopedics. 2014;37(2):e141-7.

44. Kitaoka HB, Alexander IJ, Adelaar RS, Nunley JA, Myerson MS, Sanders M. Clinical rating systems for the ankle-hindfoot, midfoot, hallux, and lesser toes. Foot Ankle Int. 1994;15(7):349-53.

45. Rome K, Survepalli D, Sanders A, Lobo M, McQueen FM, McNair P, et al. Functional and biomechanical characteristics of foot disease in chronic gout: a case-control study. Clin Biomech. 2011;26(1):90-4.

46. Pascual E, Batlle-Gualda E, Martínez A, Rosas J, Vela P. Synovial fluid analysis for diagnosis of intercritical gout. Ann Intern Med. 1999;131(10):756-9.

47. Sivera F, Aragon R, Pascual E. First metatarsophalangeal joint aspiration using a 29-gauge needle. Ann Rheum Dis. 2008;67(2):273-5.

48. Weinberger A, Schumacher HR, Agudelo CA. Urate crystals in asymptomatic metatarsophalangeal joints. Ann Intern Med. 1979;91(1):56-7.

49. Guggi V, Calame L, Gerster J-C. Contribution of digit joint aspiration to the diagnosis of rheumatic diseases. Joint Bone Spine. 2002;69(1):58-61.

50. Naredo E, Uson J, Jiménez-Palop M, Martínez A, Vicente E, Brito E, et al. Ultrasound-detected musculoskeletal urate crystal deposition: which joints and what findings should be assessed for diagnosing gout? Ann Rheum Dis. 2013.

51. Roddy E, Menon A, Hall A, Datta P, Packham J. Polyarticular sonographic assessment of gout: a hospital-based cross-sectional study. Joint Bone Spine. 2013;80(3):295-300.

52. Ottaviani S, Gill G, Aubrun A, Palazzo E, Meyer O, Dieudé P. Ultrasound in gout: A useful tool for following urate-lowering therapy. Joint Bone Spine. 2015;82(1):42-4.

53. Sun Y, Ma L, Zhou Y, Chen H, Ding Y, Zhou J, et al. Features of urate deposition in patients with gouty arthritis of the foot using dual-energy computed tomography. Int J Rheum Dis. 2015;18(5):560-7.

54. Dalbeth N, House ME, Aati O, Tan P, Franklin C, Horne A, et al. Urate crystal deposition in asymptomatic hyperuricaemia and symptomatic gout: a dual energy CT study. Ann Rheum Dis. 2015;74(5):908-11. 
55. Dalbeth N, Aati O, Kalluru R, Gamble GD, Horne A, Doyle AJ, et al. Relationship between structural joint damage and urate deposition in gout: a plain radiography and dual-energy $C T$ study. Ann Rheum Dis. 2015;74(6):1030-6.

56. Thiele RG, Schlesinger N. Diagnosis of gout by ultrasound. Rheumatology (Oxford). 2007:46(7):1116-21.

57. Thiele RG, Schlesinger N. Ultrasonography shows disappearance of monosodium urate crystal deposition on hyaline cartilage after sustained normouricaemia is achieved. Rheumatol Int. 2010;30:495-503.

58. Dalbeth N, Doyle A, Boyer L, Rome K, Survepalli D, Sanders A, et al. Development of a computed tomography method of scoring bone erosion in patients with gout: validation and clinical implications. Rheumatology (Oxford). 2011;50(2):410-6.

59. Higgins JPT, Thompson SG, Deeks JJ, Altman DG. Measuring inconsistency in meta-analyses. Br Med J. 2003;327(7414):557-60.

60. Dalbeth N, Kalluru R, Aati O, Horne A, Doyle AJ, McQueen FM. Tendon involvement in the feet of patients with gout: a dual-energy CT study. Ann Rheum Dis. 2013;72(9):1545-8.

61. Filippucci E, Meenagh G, Delle Sedie A, Sakellariou G, lagnocco A, Riente L, et al. Ultrasound imaging for the rheumatologist XXXVI. Sonographic assessment of the foot in gout patients. Clin Exp Rheumatol. 2011;29(6):901-5.

62. Roddy E, Thomas MJ, Marshall M, Rathod T, Myers H, Menz HB, et al. The population prevalence of symptomatic radiographic foot osteoarthritis in communitydwelling older adults: cross-sectional findings from the clinical assessment study of the foot. Ann Rheum Dis. 2013;74(1):156-63.

63. Zhang W, Doherty M, Pascual E, Bardin T, Barskova V, Conaghan P, et al. EULAR evidence based recommendations for gout. Part I: diagnosis. Report of a task force of the Standing Committee for International Clinical Studies Including Therapeutics (ESCISIT). Ann Rheum Dis. 2006;65(10):1301-11.

64. Rome K, Stewart S, Vandal AC, Gow P, McNair PJ, Dalbeth N. The effects of commercially available footwear on foot pain and disability in people with gout: a pilot study. BMC Musculoskelet Disord. 2013;14:278.

65. Stewart S, Dalbeth N, McNair P, Parmar P, Gow P, Rome K. The effect of good and poor walking shoe characteristics on plantar pressure and gait in people with gout. Clin Biomech. 2014;29:1158-63.

66. Rome K, Erikson K, Ng A, Gow PJ, Sahid H, Williams AE. A new podiatry service for patients with arthritis. N Z Med J. 2013;126(1370):70-7.

67. Howard RG, Pillinger MH, Gyftopoulos S, Thiele RG, Swearingen CJ, Samuels J. Reproducibility of musculoskeletal ultrasound for determining monosodium urate deposition: concordance between readers. Arthritis Care Res. 2011;63(10):1456-62.

68. Kim S-K, Lee H, Kim JH, Park S-H, Lee SK, Choe J-Y. Potential interest of dual-energy computed tomography in gout: focus on anatomical distribution and clinical association. Rheumatology (Oxford). 2013;52(2):402-3.

69. Pascual E, Sivera F. Time required for disappearance of urate crystals from synovial fluid after successful hypouricaemic treatment relates to the duration of gout. Ann Rheum Dis. 2007;66(8):056-1058.

\section{Submit your next manuscript to BioMed Central and we will help you at every step:}

- We accept pre-submission inquiries

- Our selector tool helps you to find the most relevant journal

- We provide round the clock customer support

- Convenient online submission

- Thorough peer review

- Inclusion in PubMed and all major indexing services

- Maximum visibility for your research

Submit your manuscript at www.biomedcentral.com/submit

C Biomed Central 